\title{
Telemental Health through a Racial Justice and Health Equity Lens
}

\author{
Scune Carrington, MSW, LICSW ${ }^{1}$ and Jeff Driskell, PhD, LICSW ${ }^{2}$ \\ ${ }^{1}$ Affiliation not available \\ ${ }^{2}$ Salem State University
}

November 9, 2021

\begin{abstract}
Telehealth has become an increasingly popular method of delivery of health-related services. Under the umbrella of telehealth lies telemental health (TMH). Although this type of modality has been around for quite some time, it was not until the arrival of Covid-19 during 2020-2021 that the United States healthcare system began to fully accept, embrace, and implement TMH. Due to public health restrictions related to Covid-19, in person therapy and other social services were prohibited (or restricted) thus relying on TMH. This article discusses the link between a racial justice lens, minority stress theory, health equity and identifies barriers/challenges in telemental health that do not reflect equity in health for racial minorities including Black, Indigenous, Hispanic, and Latinx communities, and all communities of color.
\end{abstract}

Telehealth has become an increasingly popular method of delivery of health-related services. The types of technology often used for telehealth include text messaging, email, telephone, and video conferencing (Maheu, 2020). Under the umbrella of telehealth lies telemental health (TMH). Although this type of modality has been around for quite some time, it was not until the arrival of Covid-19 during 2020-2021 that the United States healthcare system began to fully accept, embrace, and implement TMH. Due to public health restrictions related to Covid-19, in person care, such as psychotherapy and other social services were prohibited (or restricted) thus relying on TMH. Despite the increased need for telemental health, concerns remain that such technological advances may exacerbate racial and ethnic health disparities (Bachireddy et al., 2020).

Prior to the onset of Covid 19, Black and Latino people were less likely to use telehealth compared to White people (Anthony et al., 2018; Douglas et al., 2017). A recent report by Anthem Telehealth and behavioral health visits during COVID-19 shown increase in telehealth by $40 \%$ for Hispanic and Latinos and $28 \%$ among Black but only among those who routinely seek mental healthcare. Black people were less likely to have any type of behavioral health visits compared to White people prior to COVID-19 and that disparity persisted throughout the pandemic even with telehealth. This data is supported by another recent study which found Black people were more likely to report use of telehealth in response to the coronavirus pandemic when compared to White people (Campos-Castillo \& Anthony, 2021). This data underscores the need to be proactive in addressing and eliminating disparities which are often the result of systemic racism.

While the United States was dealing with Covid-19, they were experiencing a constellation of racially charged events such political unrest, increased visibility of White supremacy, police brutality and structural racism. It is a combination of ongoing racial injustices, physical isolation and restrictions associated with COVID-19 that has resulted in the increased need of mental health services to address such things as trauma, anxiety, and depression. Due to the immediacy and increased need for such services, the development and implementation of TMH was not fully thought through and as a result, elements of health equity were compromised.

We continue to live in a society where our healthcare system was, and remains to be, built upon a foundation 
of structural racism (e.g., policies and practices) and inequities. The social work profession as well as other behavioral health professions have not been immune to this criticism. Recently, the National Associate of Social Workers (NASW, 2021) published a report titled "undoing racism" and apologized for supporting policies and activities that harm people of color including bias among social work professionals that has negatively influences health care, mental health, and social service delivery for people of color. This report outlines NASW's strategic plan on how to take anti-racist approaches to policy and practice. In addition, in January of 2021, the American Psychiatric Association (APA) released an apology to Black, Indigenous and people of color for its support in structural racism in the field of psychiatry. These factors have contributed to the disproportionality of health and behavioral disparities among racial minorities including Black, Indigenous, Hispanic, and Latinx communities, and all communities of color.

Telemental health as a modality of service delivery has been instrumental in meeting the mental health needs of many people. While TMH technological advances have been vast and effective, this technology may exacerbate existing problem as it relates to equity in health care access for minority racial and ethnic groups. In practice, this phenomenon is known as intervention-generated inequality or better known as IGI (Veinot et al., 2018). As a member of the helping profession, broadening and shifting one's perspective can make a significant difference in addressing health disparities among racial minority communities.

\section{Perspective Taking}

To better understand the experiences of racial minorities as they relate to TMH, we can look at the situation from a convergence of two perspectives: racial justice and health equity. Racial justice is defined "as the systematic fair treatment of people of all races that results in equitable opportunities and outcomes for everyone. All people can achieve their full potential in life, regardless of race, ethnicity, or the community in which they live" (Casey foundation, 2015). According to the National Education Association (2018), "racial justice, or racial equity, goes beyond anti-racism. It is not just the absence of discrimination and inequities, but also the presence of deliberate systems and supports to achieve and sustain racial equity through proactive and preventative measures."

The other ingredient is the concept of health equity. According to the Robert Wood Johnson Foundation (2017), "Health equity means that everyone has a fair and just opportunity to be as healthy as possible. This requires removing obstacles to health such as poverty, discrimination, and their consequences, including powerlessness and lack of access to good jobs with fair pay, quality education, housing, safe environments, and health care." One of the many obstacles for achieving health equity is racial and ethnic discrimination. Therefore, addressing many of these barriers require intentionality on the part of organizations and clinicians to adapt to new technologies using a health equity lens that address disparities in communities and developing interventions that does widen the gap.

\section{Barriers to TMH}

The experience of TMH for racial minorities has brought to light, and in some cases exacerbated discrimination and unequal access to mental and behavioral care. These experiences are what continue to feed disparities in care/access and structures that foster racism. If you step back and look at TMH from both a racial justice and health equity lens, there are challenge's racial minorities experience. And while these challenges may be experienced by more dominant racial groups, racial minorities experience them at a greater degree and frequency. Noted below are some of the characteristics, challenges and practices that create barriers to TMH for racial minorities.

- White clinicians often make assumptions that ALL clients have access to the resources necessary to participate in TMH therapy without inquiry.

- Racial minorities, especially those with lower levels of education and income, are less likely to have broadband service at home. They are also known to have limited or no access to a computer, smart phone, or tablet.

- Clinicians often lack the full context in which racial minority clients live. This can be the result of poor and incomplete assessment skills. Specifically neglecting to explore experiences of trauma which 
has resulted from chronic exposure to racism, discrimination, and oppression.

- Imparting implicit bias onto clients who are racial minorities. This type of bias shows up in the form of microaggressions and within agency/organizational policies.

\section{Operationalizing Racial Justice and Health Equity into Practice}

So, you may be wondering what you can to foster racial justice and health equity while at the same time dismantling practices that continue to oppress. These strategies go beyond simply implementing TMH. They encourage us to think and act in a way that is proactive, inclusive and supports anti-racism practices. You can think of it as implementing equity minded practice. This practice requires ongoing learning and not just a one and done type of approach. There are several active steps that can be taken that foster and support practices that use a racial lens and support health equity.

1. Introduce yourself: Although introducing yourself sounds like a given, there are some elements you should consider. At the onset of working with a new client via TMH make sure to introduce yourself and how you identify (Telehealth certification institute, 2020). This is especially important when meeting with a client when there are no visual cues (e.g., meeting with the client via the phone and no video). This introduction could include your race, pronouns, a bit about your role, training, treatment modalities and experience in the services you are providing. This process is part of the informed consent and involves trust building by validating identities. For example, meeting with a new client via the phone, one may say, "Hi, Carlos, my name is Michael, I use he/him pronouns and identify as a White male. I am a licensed social worker and have been in this profession for about 8 years. I also wanted you to know that I will be providing you with services via TMH from my home office in Boston. I want to ensure you that I have all security measures in place to protect your confidentiality. Might you have any questions of me? Can you share with me a bit about who you are?"

2. Assess accessibility/resources: The concept of accessibility is broad, but for our purposes, we are looking at accessibility through a racial and health equity lens. It is often assumed that ALL clients have access to the same means necessary for TMH. To take advantage of TMH, clients need access to internet/broadband, various technologies, and digital literacy (i.e., send/receive email, access, and complete online forms). The absence of these means not only can fuel health disparities, but also to a digital divide. This divide is known to disadvantage minority racial groups including Black, and Latinx (Nouri et al., 2020). Research conducted by Pew Research Center found that Black and Hispanic adults are less likely to own a traditional computer or have broadband/highspeed internet at home as compared to White adults (Atske \& Perrin, 2021). At the onset, assess client resources to determine to what degree TMH is feasible. For example, inquire about client access to broadband services, availability of monthly allotted cell phone minutes, access to smartphone/computer/tablet. You will also want to inquire about client preference as it relates to meeting via video, phone, in person (when possible) and language preference (Nouri et al., 2020). For example, when meeting with a client for the first time via TMH make sure they have access to services and documents that are offered with their primary language either through translation services or bilingual or bicultural staff. If a barrier for clients are monthly cell phone fees, provide them with resources such as the Lifeline federal program (assists with monthly phone and internet fees) (Lyles, 2019). It is often the case that local libraries offer free Wi-Fi within their building and often in the parking lots.

3. Develop a change plan: One of the roadblocks to successfully instituting change is when there is intention and no action plan. We must do more than simply talk about change. At the most basic level, your TMH plan should include assessing your own technology, developing knowledge regarding HIPPA/confidentiality, professional licensure requirements, and evaluation (Northeast Telehealth, 2018). The American Psychiatric Association has authored a document titled, "Best Practices Video Conferencing-based Telemental health" (2018). Lacking from this document are strategies to support diversity, equity, and inclusion as they relate to race. Moreover, your plan should include consciously putting into place supports for diversity, equity, and inclusion (AMA, 2021). It is helpful to begin this process by taking an inventory and reflecting on your current practices and policies. This work should not be done in isolation. For example, collect and analyze client data to determine if there are any 
potential patterns and inequities in service delivery (Johnson, Slayter, \& Simmons 2021). Consider using NASW's strategic plan for undoing racism (NASW, 2021) to assist in creating your plan.

4. Educate yourself: Recognize that each person has their own racial and ethnic biases. Engage in your own self-examination to develop an awareness of one's own beliefs, attitudes, privileges, and biases (Cénat, 2020). Consider how these might influence your engagement and work with racial minority clients. Reflect on the impact that racism has on racial minority groups and how these experiences can shape their involvement with services. This process involves committing yourself to participating in trainings, workshops, joining a book club, following a blog all of which should have a focus on racial justice and health equity. This is an ongoing journey and not a one and done type of approach to educating oneself.

5. Join an ongoing affinity group: Affinity groups are when members of the same racial group meet on a regular basis to discuss dynamics of institutional racism, oppression, and privilege (Blitz \& Kohl 2012). The intent of affinity groups is to understand institutionalized racism and how privilege on how one experience race and foster accountability. If you are employed in an organization committed to doing antiracist work, advocate for the formation of affinity groups. If you have a private practice, join an affinity group through your association's membership. This will allow you to have ongoing conversations about race and your social work practice.

6. Advocate for change: Assess and recognize when a policy (or environment) may exclude (sometimes unintentionally) or oppress a person or racial group. This requires engaging in practices that dismantles the status quo. This involves reviewing, modifying, and developing policies that are grounded in a racial justice and health equity lens (Nouri et al., 2020). For example, does your agency or practice have policies in place around TMH that are inclusive of all groups being served? What is the evidence that indicates when policies are inclusive? Perhaps missing is a policy on accessibility for racial minority clients. This may require you to advocate for telehealth platforms with features such as captioning and integrated translation services for monolingual clinicians.

Whether you are a student, seasoned social worker, work for an agency or in the private practice arena, making a commitment to these efforts may feel hard while at the same time it is part of the social work commitment to health equity and racial justice. We suggest creating a plan where you start with one or two of the operationalizing steps versus trying to tackle all of them at once. Good luck as you commit and take on the important role of providing TMH through a racial justice and health equity lens.

\section{References}

Robeznieks, A. (2021, Aug. 27). How to implement telehealth in your practice with equity in mind. American Medical Association. https://www.ama-assn.org/practice-management/digital/how-implement-telehealthyour-practice-equity-mind

American Psychiatric Association. (2021, January 18 $\left.{ }^{\text {th }}\right)$. APA's apology to Black, Indigenous, and People of Color for its support of structural racism in psychiatry.https://www.psychiatry.org/newsroom/apa-apologyfor-its-support-of-structural-racism-in-psychiatry

American Psychiatric Association. (2018, April). Best Practices in Videoconferencing-Based Telemental Health. Retrieved

https://pubmed.ncbi.nlm.nih.gov/30358514/

Anthony, D. L., Campos-Castillo, C., Lim, P., S. (2018). Who isn't using patient portals and why? Evidence and implications from a national sample of US adults. Health Aff 37 (12), 1948-54.

Atske, S., \& Perrin, A. (2021, July 16). Home broadband adoption, computer ownership vary by race, ethnicity in the U.S. Pew Research Center. https://www.pewresearch.org/fact-tank/2021/07/16/home-broadbandadoption-computer-ownership-vary-by-race-ethnicity-in-the-u-s/

Bachireddy, C., Chen C., Dar M. (2020). Securing the safety net and protecting public health during a pandemic: Medicaid's response to COVID-19. J Am Med Assoc. 323 (20): 2009-10. 
Blitz, L.V., \& Kohl, B.G. (2012). Addressing Racism in the Organization: The Role of White Racial Affinity Groups in Creating Change. Administration in Social Work, 36 , 479-498.

Campos-Castillo, C., \& Anthony, D. (2021). Racial and ethnic differences in self-reported telehealth use during Covid-19 pandemic. A secondary analysis of a US survey of internet users from late March.Journal of the American Medical Informatics Association, 28 (1), 119-125.

Cénat, J. (2020). How to provide ant-racist mental health care.The Lancet. https://www.thelancet.com/action/showPdf?pii=S2215-0366\%2820\%2930309-6

Dr. Maheu. (2020, Aug. 6). Four Types of Telehealth: Advantages and Uses . Telehealth, https://telehealth.org/four-types-of-telehealth/

Douglas, M.D., Xu, J., Heggs, A., Wrenn G., Mack, D.H., Rust, G. (2017). Assessing telemedicine utilization by using Medicaid claims data.Psychiatry Serv 68 (2): 173-8.

Johnson, L. M., Slayter, E. M., \& Simmons, L.D. (2021). On Equity-Minded Practice as a Framework for Social Workers, The New Social Worker online https://www.socialworker.com/feature-articles/practice/equityminded-practice-framework-social-workers/

Lyles, C.R. (2019, May 7). Tackling Digital Inequality in the Tech Capital of the World. San Francisco Examiner . https://www.sfexaminer.com/opinion/tackling-digital-inequality-in-thetech-capital-of-the-world/.

National Association of Social Workers. (2021, June). Undoing racism through social work: NASW report to the profession on racial justice priorities and action.https://www.socialworkers.org/LinkClick.aspx?fileticket=29AYH9qAdXc\%3d\&portalid=0

Nouri, S., Khoong, E. C., Lyles, C.R., \& Karliner, L. (2020). Addressing Equity in Telemedicine for Chronic Disease Management During the Covid-19 Pandemic. NEJM Catalyst, DOI: 10.1056/CAT.20.0123

Northeast Telehealth Resource Center (2018, Dec.). Roadmap for planning development of clinical telemedicine services.https://netrc.org/wp-content/uploads/2015/04/NETRC-Roadmap-for-PlanningDevelopment-of-Clinical-Telemedicine-Services-2014.pdf

Robert Wood Johnson Foundation. (2017, May $\left.1^{\text {st }}\right)$. What is health equity?https://www.rwjf.org/en/library/research/2017/05/what-is-health-equity-.html

The Annie E. Casey Foundation (2015, January 8th). Race equity and inclusion action guide. https://www.aecf.org/resources/race-equity-and-inclusion-action-guide

Telehealth certification institute (2020). The Racial Justice and Community Restoration Virtual Event, Helped Clinicians Develop Cultural Competence and Meet the Needs of Racial Minority Clients. Retrieved https://www.telementalhealthtraining.com/the-racial-justice-and-community-restoration-virtualevent-helped-clinicians-develop-cultural-competence-and-meet-the-needs-of-racial-minority-clients

Veinot, T.C., Mitchell, H., \& Ancker, J.S. (2018). Good intentions are not enough: how informatics interventions can worsen inequality. Journal of American Medical Informatics Association, 25 (8). 1080-1088. 